\title{
Factors Affecting Scaling Experiences of Adolescent Children from Multicultural and Native Families
}

\author{
Eunsuk Ahn, Jin-Young Yang, and Ki-Eun $\mathrm{Kim}^{\dagger}$ \\ Department of Dental Hygiene, Daejeon Institute of Science and Technology, Daejeon 35408, Korea
}

\begin{abstract}
Background: Multicultural families are constantly on the rise as marriage migrants and foreign workers increase. Multicultural families appear to record poor health levels compared to native families. As health is a social issue, children of surviving generations of multicultural families are also a growing interest. This study was conducted to confirm the effect of multicultural families and parents' educational level on the scaling experience of children.

Methods: For this study, the 2016 2018 Korea Youth Risk Behavior Web-based Survey data were used. In order to make the two groups of adolescents belonging to multicultural and native families similar, a total of 5, 362 people were included in the survey, consisting of 2,681 individuals each from multicultural and native families using the propensity score matching method. Logistic analysis was performed to identify factors influencing the scaling experience of adolescent children.

Results: The results confirm that, even after controlling for factors such as parents' educational level, household income, and children's oral health behavior, parents' nationality appeared to have a statistically significant effect on their children's scaling experience. In addition, it was confirmed that the experience of oral health education had a significant effect.

Conclusion: Cultural heterogeneity and the lack of adequate language ability of immigrants affects health behavior and medical accessibility. Therefore, children from multicultural families are more likely to be exposed to unhealthy environments compared to the children of native Korean families. Based on an understanding of the socioeconomic multicultural background of individuals, education and public policy should be prepared to improve the awareness for the need for preventive oral health and provide unhindered accessibility to dental services.
\end{abstract}

Key Words: Adolescent, Dental scaling, Multicultural family

\section{Introduction}

According to the statistical year book of immigration and foreign policy, the number of foreigners residing in Korea has almost doubled from $1,158,866$ in 2008 , the year in which the multicultural family support policy was enacted, to 2,367,607 in $2018^{1)}$. This phenomenon naturally leads to an increase in the number of children who belong to multicultural families. According to the 2018 Youth Statistics, the number of students in multicultural families was 122,212 , accounting for approximately $2.19 \%$ of the total number of students $(5,593,000)$, an increase of $14.5 \%$ compared to $2017^{2}$. While the overall school-age population is expected to continue to decline, the proportion of children from multicultural families is expected to continue to rise in the future. Therefore, policy makers are expected to be interested in the health conditions of multicultural adolescents and children and prepare appropriate policies ${ }^{2,3)}$.

Family support is one of the most influential factors for children's growth and development. Therefore, understanding multicultural children requires understanding the characteristics of multicultural families ${ }^{4}$. In particular, the family environment of children and the degree of integration of families may differ depending on the socioeconomic characteristics of the multicultural family, such as the migration background of parents. It is necessary to 
understand the risk factors that negatively affect health behavior ${ }^{5}$. In general, members of multicultural families appear to have poor health status compared to members of native families ${ }^{5,6}$. In particular, it was found that the health of children of multicultural families is adversely affected because they are restricted from using medical services due to their parents' economic burden and lack of language skills, which are necessary to avail those services ${ }^{5)}$.

As health-related beliefs and behaviors that determine health are formed during adolescence, it is necessary to properly manage potential risk factors during this period to lead a healthy life in both adulthood and adolescence ${ }^{7,8)}$. In adolescence, gingivitis and periodontitis are prone to various causes such as lack of time for oral hygiene and stress, making oral health care necessary ${ }^{9,10)}$. Children of ethnic minority and immigrant communities are exposed to a dynamic environment with respect to cultural change ${ }^{11,12)}$. These changes in the environment may increase the risk of developing periodontal disease because it affects the family's and children's ability to cope with potential stressful situations, which in turn can affect dental procedures and visits $^{12}$. In addition, the parents of ethnic minorities who have fatalistic attitudes to health, may not actively seek preventive treatment or follow preventive recommendations ${ }^{13,14)}$. Based on reports that the environment of multicultural families is related to children's oral health, this study aims to identify differences in oral health behaviors of children according to the socioeconomic level of native and multicultural families. In addition, we would like to examine the factors that affect the adolescent children's scaling experience. At this time, in order to reduce the bias of the research study, the sample was divided into two similar groups comprising multicultural families and native families and analyzed.

\section{Materials and Methods}

\section{Research subjects}

In this study, data from 2016 2018 the "Korea Youth Risk Behavior Web-based Survey" were used. This survey is conducted by the Korea Centers for Disease Control and Prevention to determine the health status of Korean adolescents using a self-completed questionnaire survey method for middle and high school students online ${ }^{15)}$. The survey contents are divided into 14 areas such as smoking, drinking, eating habits, mental health, oral health, and health equity, and consist of a total of 125 questions ${ }^{15)}$. This study aimed to identify factors affecting oral health in native and multicultural families and adolescents. Native families were defined as those families in which the father and the mother of the child is of Korean nationality, and multicultural families were defined as those families in which the father or the mother was of another nationality. When selecting adolescents of multicultural families and native families in observational studies, selection bias may occur, and it is impossible to accurately deduce the causality of the results. In addition, such results may be prone to error, as one could overestimate or underestimate the results ${ }^{16,17)}$. Therefore, it is necessary to select a variable that can control the confounding variable in the design of the study, calculate the controlled confounding variable as a constant covariates, and then apply a similar method between the experimental group and the control group $^{18)}$. In this study, the two groups were made similar by using the propensity score matching method and a logistic regression was used for the propensity score estimation algorithm. Further, the matching algorithm was 1:1 matched using nearest neighbor matching. Covariates were gender, age, and household income, and binary treatment indicators were based on multicultural families. The number of adolescents before matching was 178,664, but after matching, it was distributed equally to 2,681 adolescents from multicultural families and 2,681 adolescents from native families (Table 1).

\section{Research variables}

In this study, we used the question "Have you been scaling in the past 12 months?" as the dependent variable. Covariate variables include gender, grade, and household income level. The independent variables included parents' nationality and educational level, adolescents' academic performance, the number of brushings per day, and participation in school oral health education in the past year.

\section{Analysis methods}

A chi-square test was conducted to compare the 
Table 1. Sample Characteristics

\begin{tabular}{|c|c|c|c|c|c|c|}
\hline PSM & Classification & Multicultural & Native & Total & $\chi^{2}$ & p-value \\
\hline \multirow[t]{10}{*}{ Before PSM $(n=178,664)$} & Gender & & & & 10.72 & $<0.001$ \\
\hline & Man & $1,288(1.40)$ & $90,640(98.60)$ & $91,928(100)$ & & \\
\hline & Woman & $1,393(1.59)$ & $86,298(98.41)$ & $87,691(100)$ & & \\
\hline & Grade & & & & 167.18 & $<0.001$ \\
\hline & Middle school & $1,683(1.86)$ & $88,815(98.14)$ & $90,498(100)$ & & \\
\hline & High school & $998(1.12)$ & $88,123(98.88)$ & $89,121(100)$ & & \\
\hline & Household income & & & & 409.47 & $<0.001$ \\
\hline & Lower & $677(2.79)$ & $23,581(97.21)$ & $24,258(100)$ & & \\
\hline & Middle & $1,305(1.56)$ & $82,542(98.44)$ & $83,847(100)$ & & \\
\hline & Higher & $699(0.98)$ & $70,815(99.02)$ & $71,514(100)$ & & \\
\hline \multirow[t]{10}{*}{ After PSM $(n=5,362)$} & Gender & & & & 0.00 & $>0.999$ \\
\hline & Man & $1,288(50.00)$ & $1,288(50.00)$ & $2,576(100)$ & & \\
\hline & Woman & $1,393(50.00)$ & $1,393(50.00)$ & $2,786(100)$ & & \\
\hline & Grade & & & & 0.00 & $>0.999$ \\
\hline & Middle school & $1,683(50.00)$ & $1,683(50.00)$ & $3,366(100)$ & & \\
\hline & High school & $998(50.00)$ & $998(50.00)$ & $1,996(100)$ & & \\
\hline & Household income & & & & 0.00 & $>0.999$ \\
\hline & Lower & $677(50.00)$ & $677(50.00)$ & $1,354(100)$ & & \\
\hline & Middle & $1,305(50.00)$ & $1,305(50.00)$ & $2,610(100)$ & & \\
\hline & Higher & $699(50.00)$ & $699(50.00)$ & $1,398(100)$ & & \\
\hline
\end{tabular}

Values are presented as number (\%).

PSM: propensity score matching.

p-value of chi-squared test.

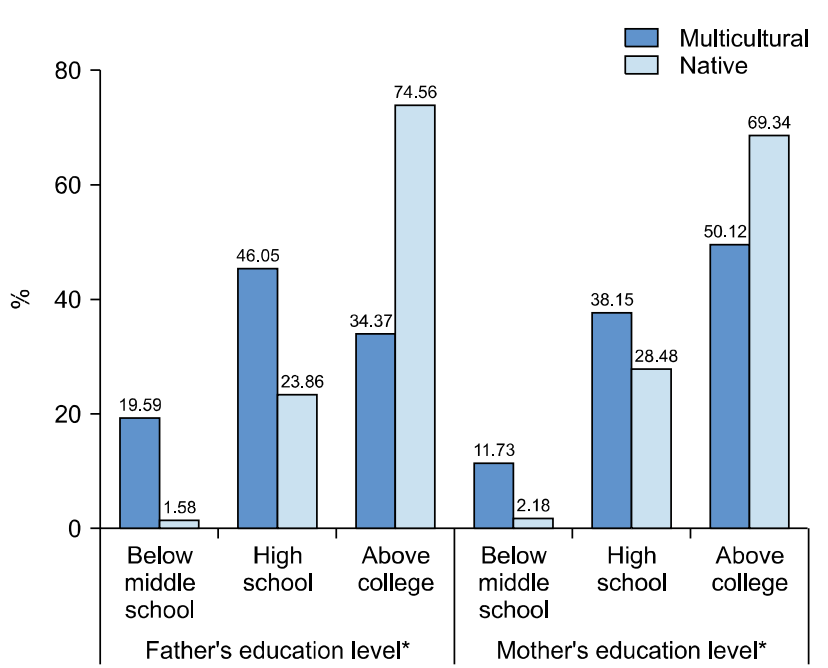

Fig. 1. Comparison of parents' educational level of multicultural and native families. $p$-value of chi-squared test. ${ }^{*} p<0.05$.

educational level of parents and educational performance of adolescents between multicultural and native families. In addition, a chi-square test was performed to examine the difference in scaling experience according to the parents' educational level, general characteristics and academic performance of adolescents. Finally, a logistic regression analysis was performed to confirm the factors influencing the scaling experience. The analysis of this study was performed using STATA software version 14.0 (Stata Corp., College Station, Tx, USA), and the statistical significance level was set to 0.05 .

\section{Results}

\section{General characteristics of research subjects}

Fig. 1 shows the results of comparing the educational level of parents of multicultural families and native families. In the case of fathers of multicultural families, "high school graduation" or higher was the highest at $46.05 \%$, and "below middle school graduation" was at $19.59 \%$ of the total population $(\mathrm{p}<0.05)$. In contrast, in the case of the fathers of a native family, "above college graduation" was highest at $74.56 \%$, and "below middle school graduation" was at $1.58 \%$, which was very low $(\mathrm{p}<$ 0.05). In terms of education level for mothers, 'above college graduation' for both multicultural and native 


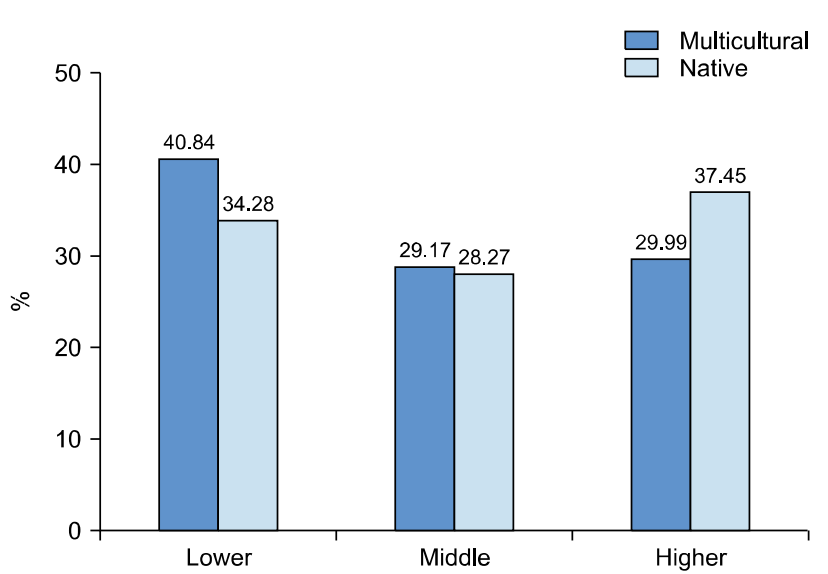

Fig. 2. Comparison of academic performance of multicultural and native families. $p$-value of chi-squared test. $p<0.05$. families was high, at $50.12 \%$ and $69.34 \%$, respectively $(\mathrm{p}<$ 0.05). Fig. 2 shows the comparison of adolescents' academic performance. In the case of multicultural family adolescents, the "Lower" group was the highest at $40.84 \%$, while for the native family adolescents, the "Higher" group was the highest at $37.45 \%(\mathrm{p}<0.05)$.

\section{Comparison of children's scaling experiences according to the characteristics of adolescents and parents' educational level}

Table 2 shows the differences in children's scaling experiences according to their general characteristics, oral health behaviors, and parents' educational level. It was

Table 2. Adolescent Children's Scaling Experience according to Parents' Educational Level and Adolescent's General Characteristics

\begin{tabular}{|c|c|c|c|c|c|}
\hline Classification & Multicultural & Native & Total & $\chi^{2}$ & p-value \\
\hline Gender & & & & 21.43 & $<0.001$ \\
\hline Man & $1,599(76.54)$ & $490(23.46)$ & $2,089(100)$ & & \\
\hline Woman & $1,616(70.35)$ & $681(29.65)$ & $2,297(100)$ & & \\
\hline Grade & & & & 2.58 & 0.11 \\
\hline Middle school & $2,040(74.13)$ & $712(25.87)$ & $2,752(100)$ & & \\
\hline High school & $1,175(71.91)$ & 459 (28.09) & $1,634(100)$ & & \\
\hline Academic performance & & & & 27.56 & $<0.001$ \\
\hline Lower & $1,240(76.59)$ & $379(23.41)$ & $1,619(100)$ & & \\
\hline Middle & $936(74.76)$ & $316(25.24)$ & $1,252(100)$ & & \\
\hline Higher & $1,039(68.58)$ & $476(31.42)$ & $1,515(100)$ & & \\
\hline Patient's nationality & & & & 29.23 & $<0.001$ \\
\hline Multicultural & $1,327(77.83)$ & $378(22.17)$ & $1,705(100)$ & & \\
\hline Native & $1,888(70.42)$ & $793(29.58)$ & $2,681(100)$ & & \\
\hline Household income & & & & 34.19 & $<0.001$ \\
\hline Lower & 849 (76.08) & $267(23.92)$ & $1,116(100)$ & & \\
\hline Middle & $1,606(75.36)$ & $525(24.64)$ & $2,131(100)$ & & \\
\hline Higher & $760(66.73)$ & $379(33.27)$ & $1,139(100)$ & & \\
\hline Father's educational level & & & & 25.83 & $<0.001$ \\
\hline Below middle school & $183(77.87)$ & $52(22.13)$ & $235(100)$ & & \\
\hline High school & 748 (74.73) & $253(25.27)$ & $1,001(100)$ & & \\
\hline Above college & $1,283(67.00)$ & $632(33.00)$ & $1,915(100)$ & & \\
\hline Mother's educational level & & & & 18.59 & $<0.001$ \\
\hline Below middle school & $133(74.72)$ & $45(25.28)$ & $178(100)$ & & \\
\hline High school & 749 (74.97) & $250(25.03)$ & $999(100)$ & & \\
\hline Above college & $1,381(67.73)$ & $658(32.27)$ & $2,039(100)$ & & \\
\hline Tooth brushing (per 1 day) & & & & 9.04 & 0.01 \\
\hline None & $69(84.15)$ & $13(15.85)$ & $82(100)$ & & \\
\hline $1 \sim 2$ times & $334(77.14)$ & $99(22.86)$ & $433(100)$ & & \\
\hline$\geq 3$ times & $2,812(72.64)$ & $1,059(27.36)$ & $3,871(100)$ & & \\
\hline Oral health education & & & & 12.54 & $<0.001$ \\
\hline No & $2,248(74.91)$ & $753(25.09)$ & $3,001(100)$ & & \\
\hline Yes & $967(69.82)$ & $418(30.18)$ & $1,385(100)$ & & \\
\hline
\end{tabular}

Values are presented as number $(\%)$.

p-value of chi-squared test. 
found that adolescent women experienced (29.65\%) more scaling than adolescent men $(23.46 \%)$. In addition, there was a positive relationship between academic performance and the incidence of scaling experience $(\mathrm{p}<0.05)$. It was found that native adolescents received more scaling by $7.41 \%$ than adolescents from multicultural families $(\mathrm{p}<$ 0.05). Similarly, it was ascertained that higher the household's income level and parents' educational level, the higher the incidence of a scaling experience $(\mathrm{p}<0.05)$. In addition, it was found that adolescents who had received oral health education at school were $5.09 \%$ more likely to experience scaling than those who did not $(\mathrm{p}<0.05)$

\section{Factors influencing adolescent children's scaling experience}

Table 3 shows the factors influencing the scaling experience of adolescent children. Firstly, children of native families were 1.28 times more likely to experience scaling than multicultural families $(\mathrm{p}<0.05)$. Scaling experience of female adolescents was a higher 1.40 times odd ratio than male adolescents $(\mathrm{p}<0.05)$. There was also a difference depending on the household's income level. In the case of the "higher" group, the scaling experience

Table 3. Factors Affecting Adolescent Children's Scaling Experience

\begin{tabular}{|c|c|c|c|c|}
\hline Classification & Odds ratio ( $95 \%$ confidence interval) & Standard error & $\mathrm{z}$ & p-value \\
\hline \multicolumn{5}{|l|}{ Gender } \\
\hline Man & (Reference) & & & \\
\hline Woman & $1.40(1.18 \sim 1.65)$ & 0.12 & 3.95 & $<0.001$ \\
\hline \multicolumn{5}{|l|}{ Grade } \\
\hline Middle school & (Reference) & & & \\
\hline High school & $1.17(0.98 \sim 1.39)$ & 0.10 & 1.75 & 0.08 \\
\hline \multicolumn{5}{|l|}{ Academic performance } \\
\hline Lower & (Reference) & & & \\
\hline Middle & $1.02(0.82 \sim 1.27)$ & 0.11 & 0.18 & 0.86 \\
\hline Higher & $1.20(0.98 \sim 1.48)$ & 0.13 & 1.76 & 0.08 \\
\hline \multicolumn{5}{|l|}{ Patient's nationality } \\
\hline Multi & (Reference) & & & \\
\hline Native & $1.28(1.04 \sim 1.56)$ & 0.13 & 2.37 & 0.02 \\
\hline \multicolumn{5}{|l|}{ Household income } \\
\hline Lower & (Reference) & & & \\
\hline Middle & $1.11(0.89 \sim 1.39)$ & 0.13 & 0.91 & 0.37 \\
\hline Higher & $1.43(1.12 \sim 1.84)$ & 0.18 & 2.81 & 0.01 \\
\hline \multicolumn{5}{|l|}{ Fathers' education level } \\
\hline Below middle school & (Reference) & & & \\
\hline High school & $1.16(0.78 \sim 1.72)$ & 0.23 & 0.73 & 0.46 \\
\hline Above college & $1.32(0.87 \sim 1.99)$ & 0.28 & 1.29 & 0.20 \\
\hline \multicolumn{5}{|l|}{ Mothers' education level } \\
\hline Below middle school & (Reference) & & & \\
\hline High school & $0.82(0.54 \sim 1.25)$ & 0.18 & -0.91 & 0.36 \\
\hline Above college & $0.95(0.62 \sim 1.45)$ & 0.21 & -0.25 & 0.81 \\
\hline \multicolumn{5}{|c|}{ Tooth brushing (per 1day) } \\
\hline None & (Reference) & & & \\
\hline $1 \sim 2$ times & $1.08(0.50 \sim 2.34)$ & 0.42 & 0.21 & 0.84 \\
\hline$\geq 3$ times & $1.39(0.68 \sim 2.86)$ & 0.51 & 0.91 & 0.36 \\
\hline \multicolumn{5}{|l|}{ Oral health education } \\
\hline No & (Reference) & & & \\
\hline Yes & $1.24(1.04 \sim 1.48)$ & 0.11 & 2.38 & 0.02 \\
\hline Constant & $0.07(0.03 \sim 0.17)$ & 0.03 & -5.78 & $<0.001$ \\
\hline
\end{tabular}

p-value of logistic regression. 
was about 1.43 times higher than the "lower" group $(\mathrm{p}<$ $0.05)$. In addition, the group that experienced school oral health education were 1.24 times more likely of receiving scaling than the group who did not experience school oral health education $(\mathrm{p}<0.05)$.

\section{Discussion}

As multicultural families increase, the interest in health gaps between members of multicultural families and native ones is increasing. In particular, the differences in the level of oral health between multicultural and native adolescents, attributed to parents' health beliefs and the lack of access to dental care caused by the unavailability of health insurance, has negative consequences for adolescents in multicultural families ${ }^{11-14,19)}$. Therefore, this study was conducted to examine the differences in scaling experiences of adolescent children between multicultural and native families and to confirm the risk factors of poor dental health of multicultural families by matching the propensity scores using the Korea Youth Risk Behavior Web-based Survey data (2016 2018).

As a result of performing a bivariate analysis using the matched data to confirm the difference in scaling experience according to the parents 'nationality and educational level and the characteristics of adolescent, there was a statistically significant difference with regards to the following independent variables: parents' nationality and educational level, children's gender, academic performance, household income, the number of brushings and school oral health education. In essence, as the level of education of parents increased, the level of scaling experience increased. These results support the findings of previous research. In previous studies, the higher the parent's education level, the higher the oral health-related knowledge and the more attention is paid to the children's oral health, but if the parent's education level is low, the oral health-related knowledge is insufficient and the children's oral health is negligible ${ }^{20,21)}$. Positive oral health behavior of a child, was associated with a higher probability of the experience of scaling as it was more likely that a preventive dental visit was undertaken. These results show that, in general, oral health behavior and scaling are classified as actions to promote oral health, so the direction of the relationship appears to be positive ${ }^{22,23)}$.

By controlling for other independent variables such as the educational level of parents of the adolescents, household income, and oral health behavior, it was ascertained that the nationality of parents was a determining factor in a positive incidence of scaling of young adolescents. A study comparing Latino children's dental health in the United States shows that immigrant children with less regular oral checkups, exhibited similar results when compared to non-immigrant children ${ }^{24)}$. In other studies, Asian immigrants' access to dental health was a hindered by disability, cultural differences, and communication difficulties. In view of these results, it seems that the patient's dental visits and the behavioral risk factors of oral health are closely related to socioeconomic factors and the cultural background of individuals. For example, in Chinese communities, there is a tendency to mix traditional and Western medical methods in treating oral diseases. Due to these cultural differences, it is thought that children of multicultural families experience less scaling for preventive dental treatment ${ }^{19)}$. Because an individual's cultural background can influence the motivation and response to health messages and spur preventive action, it can lead to marked differences in the use of dental services between different populations. In order to bridge the gap in dental care utilization that may arise from these differences, we suggest steps to improve the communication between dental staff and patients by providing interpretation and translation services. Furthermore, it is also recommended that strides are to be made to improve the awareness of patient values and beliefs of those from multicultural families by dental teams. Lastly, it is thought that recommendations and treatment plans for oral health should be provided more actively.

Adolescents who were exposed to school oral health education experienced scaling 1.24 times higher than those who did not. The purpose of oral health education is to encourage hygienic oral health habits by providing knowledge and information of the causes of oral disease and at the same time motivating educators for oral health management and establishing that prevention of oral diseases is possible ${ }^{25)}$. When appropriate oral health 
education is provided, oral health behaviors can be improved and oral health can be expected to improve accordingly. Particularly, because adolescence is a period of transition into adulthood, in which an individual undergoes physical, emotional, and social changes, it is also a period in which individuals are likely to develop lifestyle habits that persist into adulthood. In order to promote oral health not only in adolescence but also in adulthood, it is thought that efforts to improve oral health behavior through active school oral health education should be continued.

In this study, raw data from the 2016 2018 Korea Youth Risk Behavior Web-based Survey, which is representative of Korean adolescents, was analyzed, and differences in scaling experiences according to parents' nationality, educational level, and general characteristics were identified. Propensity score matching prevented underestimation in the analysis, as the number of "experimental groupmulticultural families" that are likely to occur in survey research was relatively small compared to "control group-native families". Therefore, the results of this study can be considered significant because the experimental and control groups are similarly distributed. Therefore, any inferences and estimated values are likely to be stable. In addition, the relationship between multicultural families and their children's scaling experiences was identified. These limitations of this study include the inability to establish a longitudinal relationship between the variables due to a lack of evidence from cross-sectional studies, and an inability to take into account various factors that can affect dental behavior due to the limitations of secondary data. However, this study can be meaningful in that it has tried to increase the internal validity of the research model by developing a fine grained analysis, by accounting for the influence of socio-economic conditions of multicultural families on adolescents scaling experiences.

\section{Notes}

\section{Conflict of interest}

No potential conflict of interest relevant to this article was reported.

\section{Ethical approval}

This study was approved by institutional review board of the Daejeon Institute of Science and Technology (IRB2019-002-018).

\section{Author contributions}

Conceptualization: Eunsuk Ahn. Data acquisition: Eunsuk Ahn. Formal analysis: Eunsuk Ahn. Supervision: Jin-Young Yang, Ki-Eun Kim. Writing-original draft: Eunsuk Ahn, Jin-Young Yang, Ki-Eun Kim. Writing-review \& editing: Eunsuk Ahn, Jin-Young Yang, Ki-Eun Kim.

\section{ORCID}

Eunsuk Ahn, https://orcid.org/0000-0002-9404-4826

Jin-Young Yang, https://orcid.org/0000-0002-5655-4438

Ki-Eun Kim, https://orcid.org/0000-0002-5989-9503

\section{References}

1. Choi Y, Kim E, Seon B, et al.: 2018 National multicultural family survey. Korean Women's Development Institute, Seoul, pp.31-39, 2019.

2. Retrieved September 22, 2019, from https://www.kostat.go.kr/ portal/korea/kor_nw/1/1/index.board?bmode=read\&aSeq $=3$ 74490 .

3. Kim L, Seo W: Investigating spatial patterns and urban influential factors of the school-age population using spatial econometric analysis. J Korean Reg Dev Assoc 28: 113-129, 2016.

4. Kim S, Hong C: The effect of discrimination experience and language problems on psychosocial adjustment in children with multi-cultural family: the moderating effect of egoresilience and family strengths. Korean J Youth Stud 24: 195-211, 2017. https://doi.org/10.21509/KJYS.2017.01.24.1.195

5. Kim H, Yeo J, Jung J, Baek S: Health status of marriage immigrant women and children from multicultural families and health policy recommendations. Korea Institute for Health and Social Affairs, Seoul, pp.127-192, 2012.

6. Seol D, Kim Y, Kim H, et al.: Foreign wives' life in Korea: focusing on the policy of welfare and health. Ministry of Health and Welfare, Gwacheon, pp.207-230, 2005.

7. Nicolau B, Netuveli G, Kim JW, Sheiham A, Marcenes W: A 
life-course approach to assess psychosocial factors and periodontal disease. J Clin Periodontol 34: 844-850, 2007. https://doi.org/10.1111/j.1600-051X.2007.01123.x

8. Loucks EB, Sullivan LM, Hayes LJ, et al.: Association of educational level with inflammatory markers in the Framingham Offspring Study. Am J Epidemiol 163: 622-628, 2006. https://doi.org/10.1093/aje/kwj076

9. Ma J, Cho M: Effect of health behaviors on oral health in Korean adolescents. J Korean Acad Oral Health 40: 100-104, 2016.

https://doi.org/10.11149/jkaoh.2016.40.2.100

10. Lim $\mathrm{C}, \mathrm{Oh} \mathrm{H}$ : The relationship between oral health behaviors and periodontal health status of Korean adolescents. J Korean Acad Oral Health 37: 65-72, 2013. https://doi.org/10.11149/jkaoh.2013.37.2.65

11. Brzoska P, Erdsiek F, Waury D: Enabling and predisposing factors for the utilization of preventive dental health care in migrants and non-migrants in Germany. Front Public Health 5: 207, 2017.

https://doi.org/10.3389/fpubh.2017.00201

12. Garcia RI, Cadoret CA, Henshaw M: Multicultural issues in oral health. Dent Clin North Am 52: 319-332, vi, 2008. https://doi.org/10.1016/j.cden.2007.12.006

13. Mejia GC, Kaufman JS, Corbie-Smith G, Rozier RG, Caplan DJ, Suchindran CM: A conceptual framework for Hispanic oral health care. J Public Health Dent 68: 1-6, 2008. https://doi.org/10.1111/j.1752-7325.2007.00073.x

14. Portero de la Cruz S, Cebrino J: Oral health problems and utilization of dental services among spanish and immigrant children and adolescents. Int J Environ Res Public Health 17: 738, 2020.

https://doi.org/10.3390/ijerph17030738

15. Korea Centers for Disease Control and Prevention: The 12th Korea youth risk behavior web-based survey. Ministry of Health and Welfare, Sejong, pp.50-83, 2018.

16. Jang $\mathrm{MH}$, Park CG: Risk factors influencing probability and severity of elder abuse in community-dwelling older adults: applying zero-inflated negative binomial modeling of abuse count data. J Korean Acad Nurs 42: 819-832, 2012. https://doi.org/10.4040/jkan.2012.42.6.819

17. Caliendo M, Kopeinig S: Some practical guidance for the implementation of propensity score matching. J Econ Surv 22: 31-72, 2005. https://doi.org/10.1111/j.1467-6419.2007.00527.x

18. Rosenbaum PR, Rubin DB: The central role of the propensity score in observational studies for causal effects. Biometrika 70: 41-55, 1983.

https://doi.org/10.1093/biomet/70.1.41

19. Tiwari T, Albino J: Acculturation and pediatric minority oral health interventions. Dent Clin North Am 61: 549-563, 2017. https://doi.org/10.1016/j.cden.2017.02.006

20. Choi M: Mother' oral health management behavior to their children in Iksan. Korean J Sanit 21: 36-46, 2006.

21. Kang BH, Park SN, Sohng KY, Moon JS: Effect of a tooth-brushing education program on oral health of preschool children. J Korean Acad Nurs 38: 914-922, 2008. https://doi.org/10.4040/jkan.2008.38.6.914

22. Lim MK: Differences in oral health according to socioeconomic status of adolescents - focusing on health behaviors and psychological factors. Korean J Health Educ Promot 34: 11-28, 2017. https://doi.org/10.14367/kjhep.2017.34.5.11

23. Lee WJ, Choi BY, Hwang KG: The effect of gender between the oral symptoms experience and health behavior factors. $\mathbf{J}$ Korean Soc Dent Hyg 18: 125-138, 2018. https://doi.org/10.13065/jksdh.2018.18.01.125

24. Valencia A, Damiano P, Qian F, Warren JJ, Weber-Gasparoni $\mathrm{K}$, Jones M: Racial and ethnic disparities in utilization of dental services among children in Iowa: the Latino experience. Am J Public Health 102: 2352-2359, 2012. https://doi.org/10.2105/AJPH.2011.300471

25. Holt K, Barzel R. Child and adolescent oral health issues. National Maternal and Child Oral Health Resource Center, Georgetown University, Washington, pp.1-8, 2012. 